TREE-RING RESEARCH, Vol. 63(1), 2007, pp. 27-36

\title{
TREE-RING BASED DROUGHT RECONSTRUCTION (A.D. 1855-2001) FOR THE QILIAN MOUNTAINS, NORTHWESTERN CHINA
}

\author{
QINHUA TIAN \\ Center for Arid Environment and Paleoclimate Research (CAEP) \\ Key Laboratory of Western China's Environment Systems MOE \\ Lanzhou University \\ Lanzhou, 730000, China \\ The State Key Laboratory of Loess and Quaternary Geology \\ The Institute of Earth Environment \\ Chinese Academy of Sciences \\ Xi' an 710075, China \\ Graduate School of the Chinese Academy of Sciences \\ Beijing 100039, China \\ XIAOHUA GOU*, YONG ZHANG, JIANFENG PENG, JINSONG WANG \\ Center for Arid Environment and Paleoclimate Research (CAEP) \\ Key Laboratory of Western China's Environment Systems MOE \\ Lanzhou University \\ Lanzhou 730000, China \\ and \\ TUO CHEN \\ Cold and Arid Regions Environmental and Engineering Research Institute \\ Chinese Academy of Sciences \\ Lanzhou 730000, China
}

\begin{abstract}
A juniper (Juniperus przewalskii Kom) tree-ring width chronology has been developed from the westernmost forest of the Qilian Mountains. Our analyses demonstrate both temperature and precipitation have significant effects on tree growth and that both should be considered in climate reconstruction. Thus a regional drought history (A.D. 1855-2001) is reconstructed by calibrating with a linear interpolation through four Palmer Drought Severity Index (PDSI) grid values nearest the sampling site. Our reconstruction extends the drought history of this area and also reveals that the most severe drought occurred in the 1920s. In the context of the drought history of western China, this extreme drought between 1925-1931 is consistent over a large surrounding region of Northwestern China. Multi-taper spectral analysis reveals the existence of significant 40- to 46-year, 29-year, and 2.1- to 3-year periods of variability. Overall, our study provides reliable information for the research of past drought variability in the Qilian Mountains, Northwestern China.
\end{abstract}

Keywords: dendrochronology, drought reconstruction, Qilian Mountains.

\section{INTRODUCTION}

With their high resolution and reliability, tree rings play an important role in global change studies. Tree-ring chronologies have been widely used

*Corresponding author: xhgou@1zu.edu.cn for reconstructing climatic variability in the most recent 1,000 and even 2,000 years of the Northern Hemisphere (Schweingruber 1983, 1996; Mann et al. 1999). Therefore, tree-ring based reconstructions can offer extended records to understand long-term variability of climate parameters (Briffa 
et al. 1995; Esper et al. 2002). In addition, treering research can also provide great insights into the mechanisms of climate change (Briffa et al. 1998). However, tree-ring reconstruction is complicated in regions where ring width is not only influenced by temperature, but also affected by precipitation variations. There are some conflicting results in the northeast Tibetan Plateau regarding whether tree-ring index responds to temperature or precipitation. Some results suggest the tree-ring widths are influenced by temperature variation (Wang et al. 1982; Kang et al. 1997, 2000; Liu et al. 2005; Gou et al. 2006, in press), whereas other studies indicate that the tree-ring width variations of the northeast Tibetan Plateau reflect annual precipitation variations, and not temperature (Shao et al. 2004; Zhang et al. 2003; Sheppard et al. 2004). In recent years, field observation and strict modern tree-ring studies indicate that tree growth may be significantly influenced by both temperature and precipitation on the different time scales (Liu et al. 2006). It is often difficult to separate the temperature signal from precipitation in the tree-ring chronologies. Thus soil moisture, affected by both precipitation and temperature, might realistically be the parameter most limiting to tree growth. The Palmer Drought Severity Index was developed by Palmer (1965) with the intent to measure the cumulative departure (relative to local mean conditions) in atmospheric moisture supply and demand at the surface as a means to measure the moisture condition and drought by incorporating antecedent precipitation, soil moisture supply and demand into a primitive hydrological accounting system (Dai et al. 2004).

Therefore, the Palmer Drought Severity Index (PDSI) has been successfully used in tree-ring research to reconstruct large-scale and long-term drought and wetness variability over the United States and other global land areas (Briffa et al. 1994; Cook et al. 1999, 2004; Heim 2002; LloydHughes and Saunders 2002; Ntale and Gan 2003; Dai et al. 2004; Zou et al. 2005; D'Arrigo et al. 2006). However, drought reconstructions based on tree-ring width in China are scarce except for the central Tian Shan area ( $\mathrm{Li}$ et al. 2006) and the northern He Lan Mountains ( $\mathrm{Li}$ et al., in press), which demonstrate their feasibility for drought variability research in China. Drought highlights both the extreme vulnerability of the semi-arid western China to precipitation deficits and the need to better understand long-term drought variability and its causes in Northwestern China. In the middle and east Qilian Mountains of Northwestern China, temperature and precipitation have been reconstructed from tree-ring chronologies (Gou et al. 2001, 2005; Wang, Y. et al. 2001; Kang et al. 2003; Liu et al. 2005). Here we explore the great potential of tree-ring application to drought reconstruction in the Qilian Mountains in Northwestern China.

In this paper, we have successfully reconstructed the mean PDSI value of the growing season (March-September) in the Qilian Mountains from 1855-2001. Finally, we have also compared our reconstruction with drought and disaster events that were recorded by historical documents (Yuan 1984) in Northwestern China.

\section{DATA AND METHODS}

\section{The Study Area and Site}

The Qilian Mountains, located on the northern margin of the Tibetan Plateau, lie between $93^{\circ} 30^{\prime}$ to $103^{\circ} 00^{\prime} \mathrm{E}$ and $36^{\circ} 30^{\prime}$ to $39^{\circ} 30^{\prime} \mathrm{N}$, about 850 $\mathrm{km}$ long and 200-300 km wide with peaks over 4,000 m (Tuanjie Peak, 5,826 m), which create a strong rain shadow effect for monsoons coming from the southeast (Gou et al. 2005). This region is also influenced by both continental climate and the climate of the Tibetan Plateau (Liu et al. 2005). The mean precipitation is $150-410 \mathrm{~mm}$ distributed unevenly in both space and time. The precipitation decreases from east to west, with the amount of precipitation from October to February being only 5-10 percent of the whole year's. The mean temperature is $0-5^{\circ} \mathrm{C}$ between $2,000-3,000$ $\mathrm{m}$ a.s.l elevation. Under the control of Mongolian High Pressure, winter weather in the Qilian Mountains is quite cold and dry, accompanied by sufficient sunshine, lower temperature and scarce precipitation. The amount of the annual evaporation reaches $160-250 \mathrm{~mm}$, with the greatest evaporation in June-August. The depth of frozen soil is between 120 to $250 \mathrm{~cm}$, generally beginning to freeze in mid-November and beginning to 


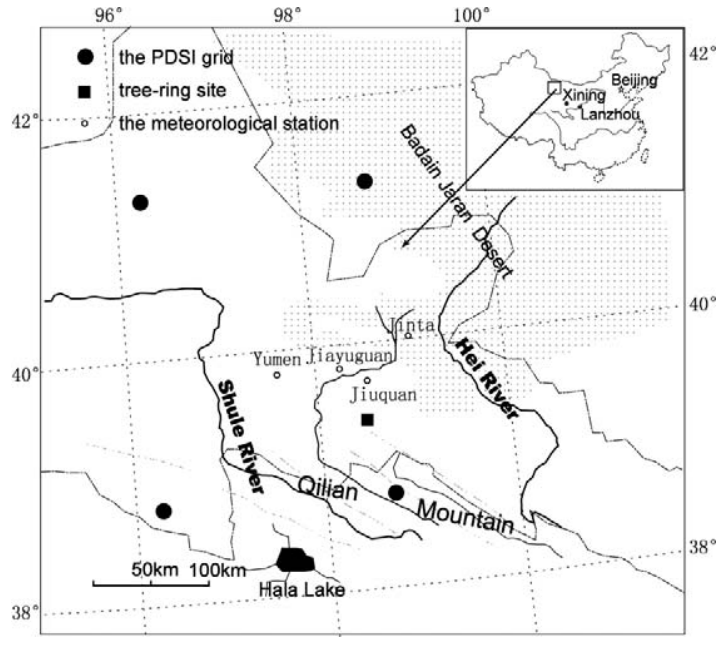

Figure 1. Map of the tree-ring sampling sites, the meteorological station and the PDSI grid points developed by Dai et al. (2004).

thaw in the last ten days of March or the first ten days of April.

The environment of the Qilian Mountains becomes increasingly arid from east to west, which results in extremely sparse forest cover in the western section. However, because of an increase in precipitation with elevation, it is characterized by a landscape of mountain forest-grassland vegetation at the elevation of 2,500-3,300 m, where maximum precipitation falls (Wang, J. et al. 2001; Zhu and Wang 1996). This promotes growth of the Qilian junipers as they occupy north-facing slopes. Our tree-ring site is in the northwestern-facing zone of a fragmentary juniper forest, which is the westernmost limit of the forest range of the Qilian Mountains (Figure 1).

The closest available meteorological station for our study is located nearby our sampling site at Jiuquan. This station record covers the period 1958-2001. Precipitation is concentrated in MaySeptember (Figure 2), coincident with the highest temperature.

\section{Tree-Ring Data and Methods}

In September 2001, 27 tree core samples were extracted from 12 living trees located at $39^{\circ} 46^{\prime} \mathrm{N}$, $98^{\circ} 29^{\prime} \mathrm{E}$. The core samples were returned to the

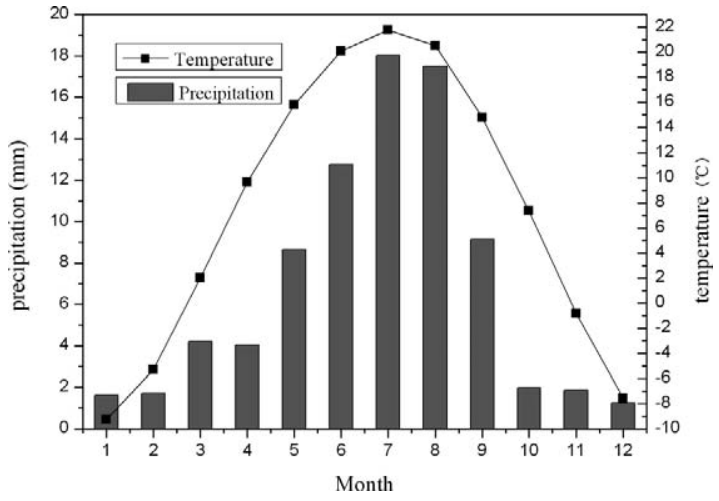

Figure 2. The pattern of monthly mean precipitation (bars) and temperature (line) at the meteorological station of JiuQuan for 1958-2001.

Lanzhou University Tree-Ring Laboratory where they were processed using standard dendrochronological techniques. After the cores were air dried, mounted, and sanded to a high polish, all samples were crossdated with skeleton plots (Stokes and Smiley 1968) and their dated ring widths measured to $0.001 \mathrm{~mm}$ precision. The quality of visual crossdating was further checked by the COFECHA program (Holmes 1983). These methods ensure exact dating for each annual ringwidth series. The average correlation coefficient among every raw measurement series and the main series is 0.68 , reflecting reliable dating of these samples.

After the tree rings were precisely crossdated and measured, the tree-ring chronology used for climate reconstruction was developed by the ARSTAN40 program (Cook 2006) using conservative detrending methods based mainly on negative exponential curves or straight lines of any slope. A cubic smoothing spline with a window width equal to $67 \%$ of the series length was also used in a few cases when anomalous growth trends occurred. Because the sample size declines in the early portion of the tree-ring chronology we used the subsample signal strength statistic (SSS; Wigley et al. 1984) with a threshold value of 0.90 chosen to determine the most reliable time span of the chronology. The starting year chosen by this procedure was 1812. Additionally, running average correlation (RBAR) and expressed population signal 


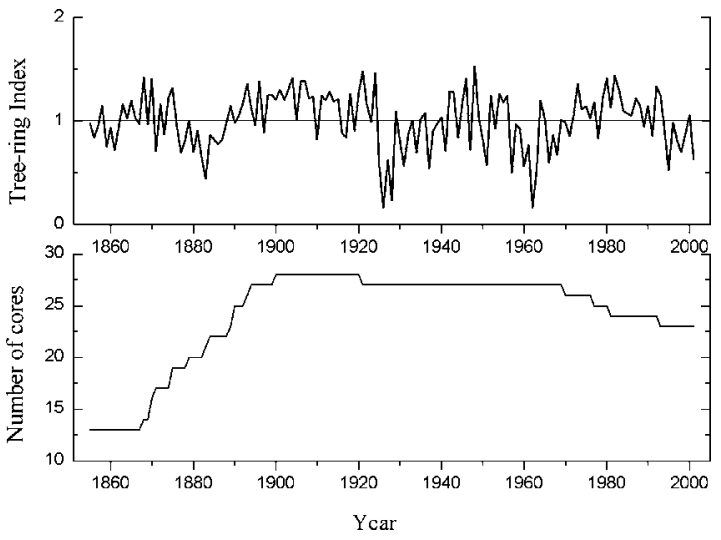

Figure 3. The reliable time span of standardized ring-width indices (upper) for the Qilian Mountains and sample size in number of cores (lower).

(EPS) statistics indicated that the chronology lost reliability prior to about 1855 . We ultimately chose the more conservative cutoff and used only that portion of our chronology back to A.D. 1855 (Figure 3 ).

The climate data used to model our tree-ring chronology were the local monthly temperature and precipitation records from the Jiuquan meteorological station near the sampling site as well as the monthly PDSI data developed by Dai et al. (2004) (Figure 1). That PDSI dataset has global coverage based on a $2.5^{\circ} \times 2.5^{\circ}$ grid. The PDSI data were processed using a bilinear interpolation of the four data grid points nearest to the sampling site. Because the four grid points used to interpolate have varying starting years, the first year of data available at each grid point varies over space. All four of these grid points have data back to 1950, so the interpolated PDSI record spans 19502001. Correlation and response functions between the tree ring and the climate data were analyzed using the DendroClimate2002 program (Biondi and Waikul 2004).

The correlations between tree growth and monthly temperature and precipitation were calculated for the common period between both data series (i.e. 1958-2001) from the prior October to the current September. As shown in Figure 4a, the current year precipitation generally correlates positively with tree-ring width index, especially in May (0.29) and June (0.41). The temperature in the current growth season, however, is mainly correlated negatively with tree growth. Statistically significant $(p<0.05)$ correlations between temperature and tree-ring width index were found in June $(-0.59)$, July $(-0.37)$ and August $(-0.45)$ in the year of growth. Likewise, July $(-0.46)$ and August $(-0.44)$ in the prior year have significant correlations that suggest a lag effect of climate on tree growth of the following year (Fritts 1976). We find that junipers (Juniperus przewalskii Kom) growing here are indeed sensitive to both the growing season temperature and precipitation. Therefore, our samples might be influenced by soil moisture, which is affected by both parameters.

This soil moisture is probably moderated by the natural conditions of our site where cool growing season temperatures aid in better conserving limited soil moisture supplies during the season of highest evapotranspiration demand. The warmest temperatures of the year are $11-19^{\circ} \mathrm{C}$ during JuneAugust in the sampling area. The precipitation of June-August is also the highest, accounting for $80-90 \%$ of the total annual precipitation (about $150 \mathrm{~mm}$ ). Summer evaporation and evapotranspiration are rather high in these arid areas, and the trees during these months are in full vigor. The available soil moisture is therefore not enough to meet the needs of biological processes. From a physiological perspective, junipers with adequate temperature and precipitation will produce wide annual rings in this period. But the soil moisture content and its rate of loss will be mainly controlled by evapotranspiration demand, which is determined mainly by temperature. If temperature is too high, soil moisture loss will be rapid and lead to physiological drought stress in the trees. In this condition, the available moisture supply can not meet the needs of tree growth and a narrow ring will be produced. Therefore the soil moisture should be the direct limiting factor for the tree growth here. Thus, PDSI may be an appropriate climate parameter to reconstruct from our juniper tree-ring width chronology.

For this reason, we further analyzed the correlations and response between our tree-ring chronology and the PDSI values in order to further 
characterize the climatic response. The correlations between tree-ring index and the monthly PDSI data were analyzed for the period of current growth season (i.e. March-September). As shown in Figure $4 \mathrm{~b}$, the correlations were significant at the $95 \%$ confidence level, especially in June ( $\mathrm{r}=$ $0.63)$. These results indicate that tree growth is highly sensitive to PDSI during the whole growing season, and that the signal strength is strong enough for climate reconstruction. The development of drought reconstructions derived from our sensitive tree-ring chronologies follows.

\section{RESULTS}

\section{Reconstruction}

Generally, past experience indicates that as seasonally averaged PDSI is more representative than just one single month, we used the seasonally average PDSI for further analysis. In addition, the peak correlation between PDSI and tree-ring index shifted from June to July, and even to August for some chronologies in different areas. This shift was attributed to regional differences in phenology (i.e. the timing of tree growth) associated with the northward March of the growing season in spring, and to the time required for evaportranspiration demand to significantly draw down the soil moisture supply (Cook et al. 1999).

After combining the months that have high correlation between PDSI and tree rings, we found that the correlation $(\mathrm{r}=0.65, \mathrm{p}<0.001)$ between the tree ring and the growing season (i.e. March to September) PDSI value was high and significant. Based on this result and the above theory, we felt growing-season PDSI would be most successfully reconstructed in the western Qilian Mountains.

A linear regression model (Cook and Kairiukstis 1990) was developed to reconstruct drought in the west of Qilian Mountains. Analysis indicated that the Standard (STD) tree-ring width chronology had the highest correlation with the PDSI value among the three types of tree-ring chronologies (Standard, Residual, and Arstan). Therefore, the STD tree-ring width chronology was used in the following model, where the subscripts (3-9) de-
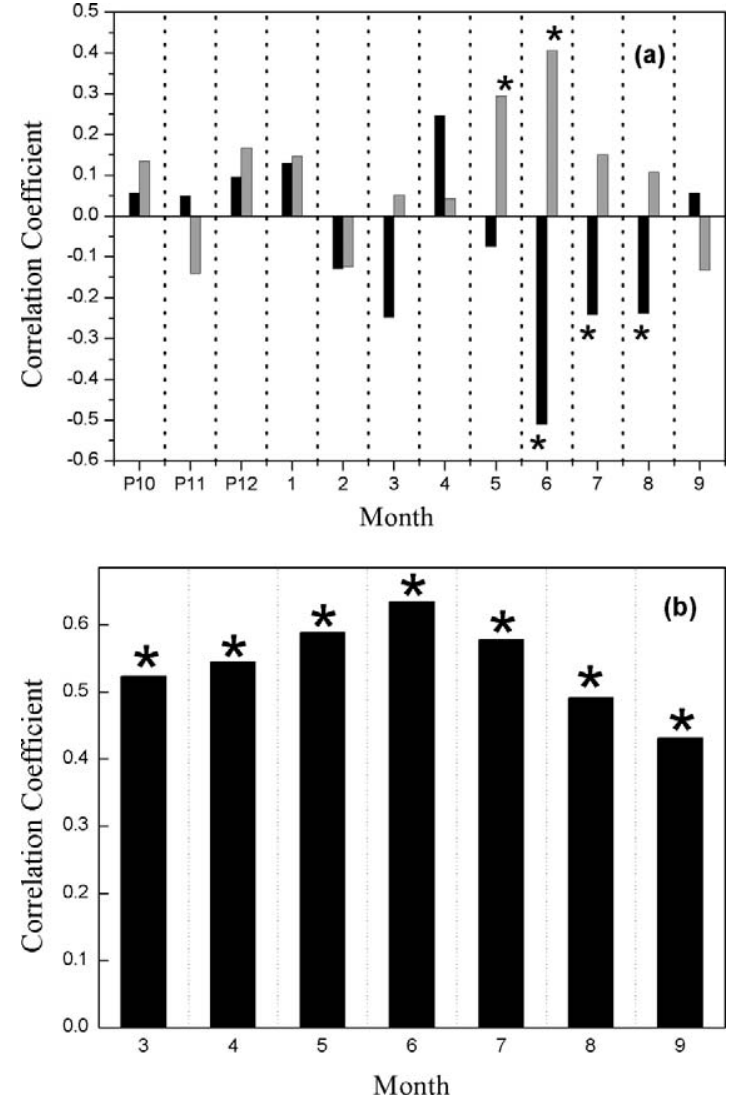

Figure 4. Correlation coefficients of tree-ring data with (a) monthly temperature (dark bars) and precipitation (light bars) records for the period of a biological year, and (b) the monthly PDSI data for the growth season. These asterisks indicate correlations at over $95 \%$ confidence level.

note the reconstruction period of March to September:

$$
\operatorname{PDSI}_{(3-9)}=-5.456+5.469 \times \mathrm{STD}
$$

The comparison of the actual and reconstructed drought is shown in Figure 5. The statistical fidelity of this model was also examined by crossvalidation tests. As shown in Table 1, the results of the statistics of the calibration indicate that our regression model is valid. The correlation coefficient is significant at $\mathrm{p}<0.001$ level. The positive RE test result indicates that the model has significant skill in tree-ring estimates. The reconstruction accounts for $42.3 \%$ of the actual PDSI variance during 1950-2001, which is very strong and 


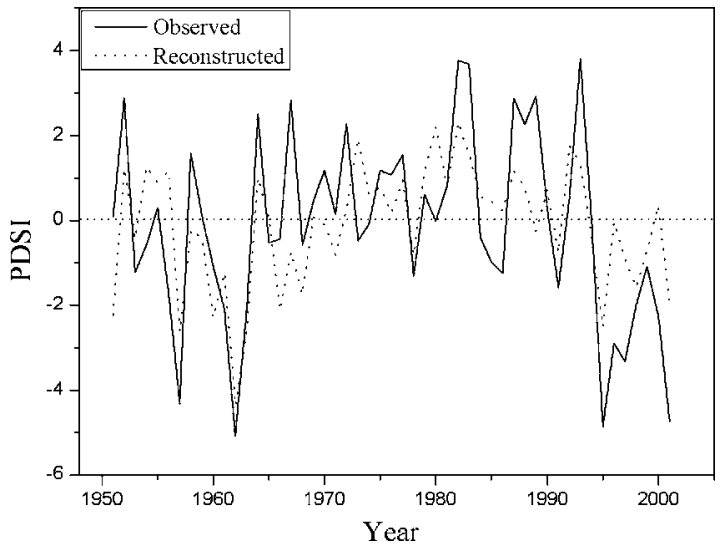

Figure 5. Observed (solid line) and reconstructed average PDSI (dotted line) from March to September for A.D. 19502001.

significant. The overall test results sufficiently support the validity of our regression model.

\section{DISCUSSION}

The reconstructed reliable PDSI spans A.D. 1855-2001, and its 5-year FFT (Fast Fourier Transform) smoothed running average tracks the long-term trends (Figure 6a). The evolution of PDSI accumulated anomalies (Figure 6c) can also be used to identify long-term trends of dryness (or wetness). Increase in PDSI accumulated anomalies indicates a trend of moisture persistence, whereas drought persistence is indicated by a decrease in the accumulated anomalies. Drought classification according to the area affected has been reconstructed from historical documents of Northwestern China (Yuan 1984). The drought classification is quantified from 6 (large) to 1 (small), as shown in the histograms in Figure $6 b$.

PDSI can quantify the drought and wet spells of arid and semi-arid areas to a certain extent. PDSI is a standardized measure of surface moisture conditions, ranging from about -10 (dry) to +10 (wet), that allows comparisons across space and time. In addition, quantitative interpretations of dryness or wetness for a given PDSI value depend on local mean climate conditions. For example, a PDSI value of +4 may imply floods in the United States, but only moderate rainfall in
Table 1. Statistics of the Calibration and Verification Test Results for the period of 1950-2001.

\begin{tabular}{|c|c|c|c|c|c|c|}
\hline $\mathrm{R}$ & $\mathrm{R}^{2}$ & $\mathrm{~F}$ & S1 & S2 & $\mathrm{t}$ & RE \\
\hline 0.65 & 0.423 & $36.62 ?$ & $35\left(35^{* *}, 33^{*}\right)$ & $37\left(35^{* *}, 32 *\right)$ & 3.46 & 0.38 \\
\hline
\end{tabular}

Note: R, correlation between observation and estimated series; $\mathrm{R}^{2}$, the explained variance; F, F statistic (Fritts 1991); the sign test is the sign of paired observed and estimated departures from the mean on the basis of the number of agreements or disagreements (S1, S2); S1 is the general sign test between observation and reconstruction that measures the associations at all frequencies; S2, which reflects the high-frequency climatic variations, is a similar test to above, and it is made for the first differences; $* *$ Indicate that the significance is at the 0.01 level and $*$ Indicate that the significance is at the 0.05 level; $t$, product mean; RE, reduction of error.

northern Africa (Dai et al. 2004). Our reconstructed PDSI values fall mainly within \pm 3 (Figure 6a), which is far lower than the PDSI amplitude of the actual data ( \pm 5 ; Figure 5$)$. In addition, generally speaking the moisture status $(\mathrm{PDSI}=0.0 \pm 0.5)$ was defined as normal (Palmer 1965). The mean value of our PDSI reconstruction is 0.014 , which is within the scale of the defined normal moisture status (PDSI $=0.0 \pm 0.5)$. So, referring to $\mathrm{Li}$ et al. (2006), where PDSI values of $\leq-1.0$ or $\geq 1.0$ represent severely dry or wet conditions and the values of $\leq-2.0$ or $\geq 2.0$ represent extremely dry or wet conditions, we interpret the reconstruction below.

According to the accumulated anomalies, the reconstructed PDSI can be approximately divided into four intervals: 1855-1890, 1890-1924, 19251971, and 1972-2001 (Figure 6c). The moisture condition of the middle and late 19th Century (i.e. A.D. 1855-1890) is near normal. Meanwhile, the dry and wet spells were almost stable and symmetrical. After that, from 1890 to 1924, the moisture state persisted higher than other periods within the reconstruction. The years of PDSI $>1$ accounted for $65.7 \%$ (23 years), the years of PDSI $<0$ accounted for $20 \%$ (7 years) and the dry years of PDSI $<-1$ were absent during the A.D. 1890 1924. From the reconstructed PDSI accumulated anomalies (Figure 6c), we can see that the anomalies slowly decreased from 1855 to 1890 , and then began a comparatively rapid increase from 


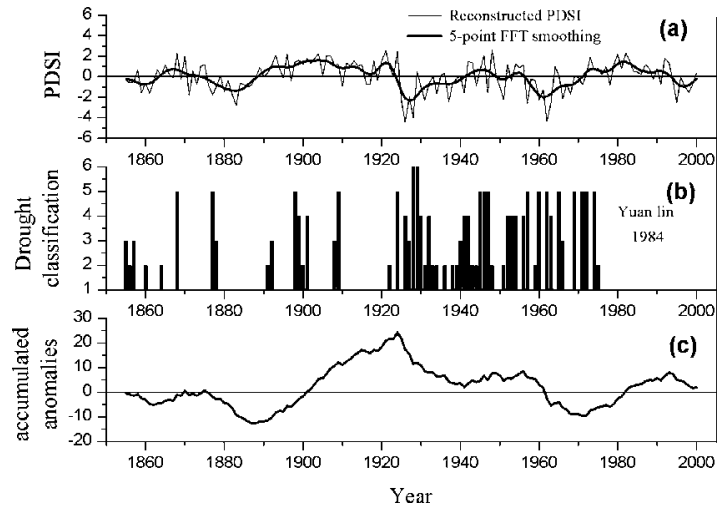

Figure 6. (a) Reconstruction drought of March-September (top solid line) for A.D. 1855-2001 and its 5-year FFT (Fast Fourier Transform) smoothing running average (bold line). (b) Drought classification of Northwestern China for A.D. 1855-1970 (bars) from the document record, the drought designations ranging from severe (6) to weak (1). (c) Reconstructed PDSI accumulated anomalies.

1890 until 1924. The comparison between the drought classified from the documents (Figure 6b) and reconstructed PDSI shows that they are consistent with a high mean value of moisture during 1855-1890. This confirms that reconstructed PDSI is reliable.

The 20th Century was comparatively dry. Drought (PDSI $\leq-1.0$ ) and extreme drought (PDSI $\leq-2.0$ ) conditions occurred in 19251931, 1934, 1937, 1941, 1947, 1951, 1957, 1960-1963, 1966, 1968, 1995, 1998 and 2001. PDSI values in 1925-1931 and 1957-1963 reached -4 , revealing the extremely dry conditions. Long conspicuous dry epochs during 1924-1971 (Figure 6a) (PDSI < 0) accounted for $61.7 \%$ (29 years) of the record, years with PDSI $<-1$ accounted for $36 \%$ (17 years), and extremely dry years (PDSI $<-2$ ) accounted for $23.4 \%$ (11 years) during the 1924-1971 period. Likewise, the accumulated anomalies (Figure 6c) decrease during this period, indicating the persistent drought. The drought documents (Figure 6b) and reconstructed PDSI are both consistent with a high mean value of dryness for 1924-1971 and indicate that drought disasters were conspicuously frequent during this period over Northwestern China. Thus we conclude that 1924-1971 was a comparatively dry epoch in the Qilian Mountains.

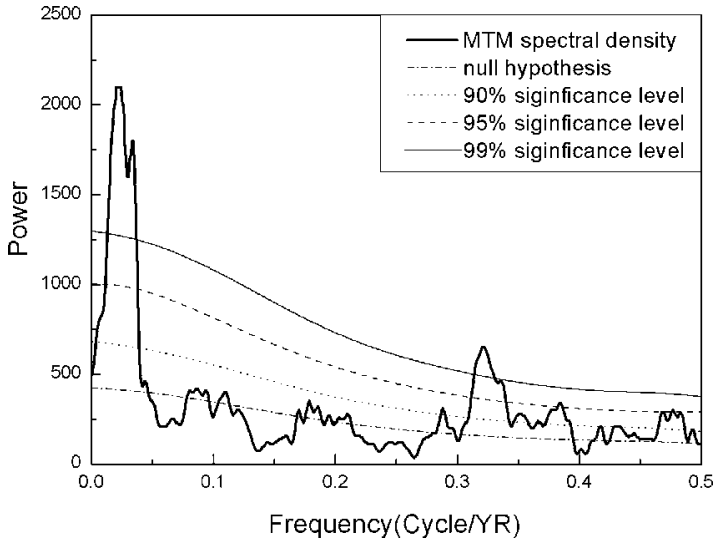

Figure 7. Results of MTM spectral analysis of the drought reconstruction. The dotted, dashed, and solid lines indicate the 90, 95 and 99\% significance level, respectively; the dash-dotted line indicates the null hypothesis.

After that, the drought and wet spell variance was almost symmetrical and stable.

It is noteworthy that the drought epoch in 19251931 is the most severe and long-lasting drought in the study area since A.D. 1855. This drought has been found to extend over a large geographic area, seen in many studies in the surrounding regions ( $\mathrm{Li}$ et al. 2006). In addition, the 1920s were reported as a severe drought epoch with high temperature and low precipitation in Northwestern China (Yuan 1984; Liang et al. 2003, 2006; Zhang et al. 2005).

The multi-taper method (MTM) of spectral analysis (Mann and Lees 1996) was employed to examine the characteristics of the drought variability in the frequency domain. It is helpful to study non-randomness in time series using spectrum analysis (Fritts 1976). The analysis over the range of our reconstruction revealed low- and high-frequency cycles (Figure 7). Both high-frequency (3 year) and low-frequency peaks (29, $40-46$ years) exceed the $99 \%$ significant confidence level based on a red noise null continuum. Other significant high-frequency cycles were found at 2.6 year and 2.1 year (95\%), 3.1 year, 2.9 year and 2.3 year $(90 \%)$.

Climatic cyclicity with a period of about 35 years (ranging from 28 year to 42 year) is known as the Bruckner cycle, discovered more than one 
hundred years ago (Raspopova et al. 2004). The occurrence of this cycle is related to variations in the length of the sunspot cycle (Wang et al. 2000). In our reconstruction, the strong peaks in oscillations (40-46 year, and 29 year) resemble Bruckner cycles and may indicate solar forcing. It suggests a possible important connection of local drought variability and solar activity.

These high-amplitude inter-annual cycles (i.e. $3,3.1,2.9,2.3,2.1$ year) may correspond to the well-known ENSO and quasi-biennial oscillations. The climate of the Qilian Mountains is affected mutually by the South Asian monsoon, East Asian sub-tropical high pressure monsoon, and the effects of heating of the Tibet Plateau. Therefore, these high-frequency cycles suggest the drought variability in our study area may respond strongly to large-scale ocean-atmosphereland circulation systems.

\section{CONCLUSIONS}

With respect to long-term presence of dry and wet spells in this region, two stages were conspicuous in our reconstruction: the wet spell of 18901924 and the dry spell of 1925-1931 (Figure 6). The MTM results indicate the existence of some important cycles for regional drought variability, possible climatic mechanisms, and relationships with global change.

The results of our study again show that it is feasible to combine tree-ring data and the PDSI for drought reconstructions in Northwestern China. Our reconstruction also provides a measure of local drought variability, which can then be compared regionally. It is a useful method to help us understand the cause and mechanisms for the decreasing sensitivity between the tree growth and the direct record of temperature and precipitation.

However, because our PDSI reconstruction is based on only a single tree-ring site, it is very important to develop large-scale and long-term drought networks in Northwestern China, similar to reconstructions in the Western United States from a dense network of annual tree-ring chronologies (Cook et al. 2004). These efforts will enable us to better understand drought trends and their characteristics in Northwestern China.

\section{ACKNOWLEDGMENTS}

We were grateful to Edward R. Cook, Aiguo Dai, Yu Liu, Qiufang Cai and Meilin Yang. This research was funded by National Science Foundation of China Project (grant No. 40671191 and 90502008), Innovation Team Project (grant No. 40421101), Program for New Century Excellent Talents in University (grant No. NCET-05-0888) and Chinese 111 Project (No. B06026).

\section{REFERENCES CITED}

Biondi F., and K. Waikul, 2004. DENDROCLIM2002: A C ++ program for statistical calibration of climate signals in treering chronologies. Computers \& Geosciences 30:303-311.

Briffa, K. R., P. D. Jones, and M. Hulme, 1994. Summer moisture variability across Europe 1892-1991: An analysis based on the Palmer drought severity index. International Journal of Climatology 14:475-506.

Briffa, K. R., P. D. Jones, F. H. Schweingruber, and T. J. Osborn, 1998. Influence of volcanic eruption on Northern Hemisphere summer temperature over the past 600 years. Nature 393:450-454.

Briffa, K. R., P. D. Jones, F. H. Schweingruber, S. G. Shiyatov, and E. R. Cook, 1995. Unusual twentieth-century summer warmth in a 1,000-year temperature record from Siberia. $\mathrm{Na}$ ture 376:156-159.

Cook, E. R., D. M. Meko, D. W. Stahle, and M. K. Cleaveland, 1999. Drought reconstructions for the continental United States. Journal of Climate 12:1145-1162.

Cook, E. R., C. A. Woodhouse, C. M. Eakin, D. M. Meko, and D. W. Stahle, 2004. Long-term aridity changes in the western United States. Science 306:1015-1018.

Dai, A., K. E. Trenberth, and T. Qian, 2004. A global dataset of Palmer Drought Severity Index for 1870-2002: Relationship with soil moisture and effects of surface warming. Journal of Hydrometeorology 5:1117-1130.

D'Arrigo R., R. Wilson, J. Palmer, P. Krusic, A. Curtis, and J. Sakulich, 2006. Monsoon drought over Java, Indonesia, during the past two centuries. Geophysical Research Letters 33: L04709, doi: 10.1029/2005GL025465.

Esper, J., E. R. Cook, and F. H. Schweingruber, 2002. Lowfrequency signals in long tree-ring chronologies and the reconstruction of past temperature variability. Science 295: 2250-2253.

Fritts, H. C., 1976. Tree Rings and Climate. Academic Press, London.

Gou, X., F. Chen, G. Jacoby, E. Cook, M. Yang, J. Peng, and Y. Zhang, 2007. Rapid tree growth with respect to the last 
400 years in response to climate warming, northeastern $\mathrm{Ti}$ betan Plateau. International Journal of Climatology. in press.

Gou, X., F. Chen, Y. Wang, and X. Shao, 2001. Reconstruction of the eastern of Qilian Mountains spring precipitation of the recent 280a from tree ring width data. Journal of Glaciology and Geocryology 23:292-295.

Gou, X., F. Chen, M. Yang, G. Jacoby, J. Peng, and Y. Zhang, 2006. A comparison of tree-ring records and glacier variations over the past 700 years, northeastern Tibetan Plateau. Annals Glaciology 43:86-90.

Gou, X., F. Chen, M. Yang, J. Li, J. Peng, and L. Jin, 2005. Climatic response of thick leaf spruce (Picea crassifolia) tree-ring width at different elevations over Qilian Mountains, Northwestern China. Journal of Arid Environments 61:513524.

Heim, R. R., Jr., 2002. A review of twentieth-century drought indices used in the United States. Bulletin of the American Meteorological Society 83:1149-1165.

Holmes, R. L., 1983. Computer-assisted quality control in treering dating and measurement. Tree Ring Bulletin 43:69-95.

Kang, X., L. J. Graumlich, and P. R. Sheppard, 1997. A 1835 year tree-ring chronology in Qinghai province, China and its preliminary analysis. Chinese Science Bulletin (in Chinese) 42(10):70-75.

Kang, X., Q. Zhang, and L. J. Graumlich, 2000. Reconstruction of a 1835a past climate for Dulan, Qinghai Province, using tree rings. Journal of Glaciology and Geocryology (in Chinese) 22(1):65-72.

Kang, X., G. Cheng, F. Chen, and X. Gou, 2003. A record of drought and flood series by tree ring data in the middle section of Qilian Mountain since 904 A.D. Journal of Glaciology and Geocryology 25:518-525.

Li, J., X. Gou, E. R. Cook, and F. Chen, 2006. Tree-ring based drought reconstruction for the central Tien Shan area in northwestern China. Geophysical Research Letters 33, L07715, doi: 10.1029/2006GL025803.

Li, J., F. Chen, E. R. Cook, X. Gou, and Y. Zhang, 2007. Drought reconstruction for north central China from tree rings: The value of the Palmer drought severity index. International Journal of Climatology, doi: 10.1002/joc.1450. in press.

Liang, E., X. Liu, and Y. Yuan, 2006. The 1920s drought recorded by tree rings and historical documents in the semiarid and arid areas of northern China. Climatic Change 79: 403-432.

Liang, E., X. Shao, Z. Kong, and J. Lin, 2003. The extreme drought in the 1920s and its effect on tree growth deduced from tree ring analysis: a case study in North China. Annals of Forest Science 60:145-152.

Liu, Y., Z. An, H. Ma, Q. Cai, and Z. Liu, 2006. Precipitation variation in the northeastern Tibetan Plateau recorded by the tree rings since 850 A.D. and its relevance to the Northern Hemisphere temperature. Science in China Ser. D Earth Sciences 49(4):408-420.

Liu, X., D. Qin, X. Shao, T. Chen, and J. Ren, 2005. Temperature variations recovered from tree-rings in the middle Qilian Mountain over the last millennium. Science in China Ser. D Earth Sciences 48(4):521-529.
Lloyd-Hughes, B., and M. A. Saunders, 2002. A drought climatology for Europe. International Journal of Climatology 22:1571-1592.

Mann, M. E., R. S. Bradley, and M. K. Hughes, 1999. Northern Hemisphere temperature during the last millennium: Influences, uncertainties and limitations. Geophysical Research Letters 26:759-762.

Mann, M. E., and J. M. Lees, 1996. Robust estimation of background noise and signal detection in climatic time series. Climatic Change 33:409-445.

Ntale H. K., and T. Y. Gan, 2003. Drought indices and their application to East Africa. International Journal of Climatology 23:1335-1357.

Palmer, W. C., 1965. Meteorological Drought. U.S. Weather Bureau Research Paper. No. 45, Washington, D.C.

Raspopova, O. M., V. A. Dergachevb, and T. Kolström, 2004. Periodicity of climate conditions and solar variability derived from dendrochronological and other palaeoclimatic data in high latitudes. Palaeogeography, Palaeoclimatology, Palaeoecology 209:127-139.

Schweingruber, F. H., 1983. Der Jahrring. Standort, Methodik, Zeit und Klima in der Dendrochronologie. Paul Haupt, Bern.

Schweingruber, F. H., 1996. Tree Rings and Environment. Paul Haupt, Bern.

Shao, X., L. Huang, H. Liu, E. Liang, X. Fang, and L. Wang, 2004. Reconstruction of precipitation variation from tree rings in recent 1000 Years in Delingha, Qinghai. Science in China (D) 34(2):145-153.

Sheppard, P. R., P. E. Tarasov, and L. J. Graumlich, 2004. Annual precipitation since 515 B.C. reconstructed from living and fossil juniper growth of northeastern Qinghai Province, China. Climate Dynamics 23:869-881.

Wang, J., X. Chang, S. Ge, Y. Miao, Z. Chang, and H. Zhang, 2001. Vertical distribution of the vegetation and water and heat conditions of Qilian Mountain (Northern slope). Journal of Northwestern Forestry University 16:1-3.

Wang, N., L. G. Thompson, and J. Cole-Dai, 2000. The nature of the solar activity during the Maunder Minimum revealed by the Guliya ice core record. Chinese Science Bulletin 45(23):2118-2124.

Wang, Y., F. Chen, X. Gou, and S. Du, 2001. Study on response relationship between tree ring and climate factors and climate reconstruction in middle region of Qilian Mountains. Journal of Desert Research 21:135-140.

Wang, Y., G. Liu, and X. Zhang, 1982. Relationship between Sabina Przewalskii ring-width, and climatic variation in China for the last 1000 years and glacier advance and retreat. Chinese Science Bulletin (in Chinese) 27(21):1316-1319.

Wigley, T., K. R. Briffa, and P. D. Jones, 1984. On the average value of correlated time series, with applications in dendroclimatology and hydrometeorology. Journal of Climate and Applied Meteorology 23:201-213.

Yuan, L., 1984. The Northwestern Drought and History of the Famine (in Chinese). The People's Publishing company of Gansu province.

Zhang, Q., G. Chen, T. Yao, X. Kang, and J. Hang, 2003. A 2,326-year tree-ring record of climate variability on the 
northeastern Qinghai-Tibetan Plateau. Geophysical Research Letters 30(14):1739-1742.

Zhang, Y., X. Gou, W. Hu, J. Peng, and P. Liu, 2005. The drought events recorded in tree ring width in Helan Mountain over past 100 years. Acta Ecologica Sinica 25: 2121-2125.

Zhu, S., and Q. Wang, 1996. Temporal-spatial distributions and recent changes of precipitation in the northern slope of the
Qilian Mountains. Journal of Glaciology and Geocryology 18:296-304.

Zou, X., P. Zhai, and Q. Zhang, 2006. Variations in droughts over China: 1951-2003. Geophysical Research Letters 32: L04707. doi: 10.1029/2004GL021853.

Received 1 September 2006; accepted 30 March 2007. 